\title{
High resolution electrophoretic variation at the esterase-6 locus in a natural population of Drosophila melanogaster
}

\author{
Peter H. Cooke \\ Rollin C. Richmond* and \\ John G. Oakeshott
}

\begin{abstract}
Department of Evolutionary Biology, Research School of Biological Sciences, Australian National University, PO Box 475, Canberra City, A.C.T., Australia 2601
\end{abstract}

\begin{abstract}
One hundred and fifty-seven lines isoallelic for esterase-6 were extracted from a natural population of $D$. melanogaster. The relative electrophoretic mobilities of Est6 allozymes in the different lines were determined by repeated pair-wise comparisons on high resolution cellulose acetate plates. Ten allozymic classes were resolved among the lines where only four, Est6-VF, Est6-F', Est6-F and Est6-S, had been evident using standard electrophoretic procedures. The additional variation resulted from the subdivision of Est6-F and Est6-S into three and five classes respectively. Genetic analyses confirmed that the additional classes mapped at or near the Est6 locus. Two of the additional classes occurring at low population frequencies were associated with significantly higher third chromosome viabilities. The most frequent class within $E s t 6-F$ was in significant gametic disequilibrium with the linked polymorphic inversion $\operatorname{In}(3 L) P$. The same high resolution procedures were applied to 13 lines of $D$.melanogaster representing six Est6 thermostability variants. Different thermostability variants did not group consistently according to electrophoretic classes. This implies that the two criteria are detecting protein variation independently from each other and that much greater variation occurs than is detected by either criterion alone.
\end{abstract}

\section{INTRODUCTION}

Knowledge of the extent of amino acid polymorphism is critical to an understanding of the evolutionary processes operating on proteins (Lewontin) 1974; Kimura, 1983). The first applications of electrophoretic procedures to this issue revealed unexpectedly high levels of polymorphism and the recent use of more sensitive electrophoretic procedures has revealed even higher levels (Nevo, 1978; Coyne, 1982, for review). For example, the xanthine dehydrogenase and esterase-5 polymorphisms of Drosophila pseudoobscura have now been resolved into 21 and 41 electrophoretic classes respectively (Keith, 1983; Keith et al., 1985). It is now clearly important to test the generality of such high levels of polymorphism and to assess their effects on fitness.

The esterase-6 (E.C. 3.1.1.1) gene-enzyme system of $D$. melanogaster is well suited to such purposes, because much is known of its physiological function and standard electrophoretic procedures have already revealed polymorphic Est6

\footnotetext{
* Present address: Department of Biology, Indiana University, Bloomington, Indiana 47405 , U.S.A.
}

allozymes whose geographic distributions strongly suggest the action of natural selection (c.f. Est5 above, Yamazaki et al., 1983). Est6 is produced in the anterior ejaculatory duct of adult males, from where it is transferred to the female during copulation (Sheehan et al., 1979; Richmond and Senior 1981). The presence of transferred Est6 in the females stimulates sperm utilisation and oviposition and affects her latency to remating (Gilbert, 1981; Scott, 1986). D. melanogaster and its sibling species $D$. simulans are both polymorphic for the same two major Est6 allozymes (Cabrera et al., 1982 and references therein), and the action of natural selection between these allozymes is suggested by parallel latitudinal clines in gene frequencies in both species and on all three continents for which data have been collected (Oakeshott et al., 1981; Anderson and Oakeshott, 1984).

Here, we report the application of more sensitive electrophoretic procedures to survey Est6 variation in an Australian population of $D$. melanogaster. We have used a technique based on cellulose acetate electrophoresis, the resolving power of which we first calibrated against 25 Est 5 variants in $D$. pseudoobscura distinguised by sequential polyacrylamide gel electrophoresis by 
Keith (1983). Progeny from test crosses were analysed in order to check that the additional Est6 variants detected mapped to the Est6 locus. Est6 variants were also tested for gametic disequilibrium with third chromosome viability modifiers and inversion polymorphism. Finally, lines from another $D$. melanogaster population representing six Est6 alleles differentiated by thermostability criteria (Cochrane, 1976; Cochrane and Richmond, 1979) were analysed with the cellulose acetate system to determine whether the two criteria resolve the same variation.

\section{MATERIALS AND METHODS}

One hundred and fifty-seven individual third chromosomes were isolated from a population at Coffs Harbour, N.S.W., using a routine backcrossing program to a standard balancer third chromosome, TM3 (Lindsley and Grell, 1968). Forty-four wild chromosomes were sufficiently viable that they could be isolated and maintained as homozygous lines. One hundred and thirteen chromosomes which were lethal or semi-lethal as homozygotes were crossed to a stock heterozygous for TM3 and a $D f(3)$ vin $^{7}$ chromosome deleted for the Est6 region (cytological locations of the Df(3) vin $^{7}$ deletion breakpoints are 68C8-11 to 69B4-5, while Est6 is at 69A1; Akam et al., 1978). Progeny heterozygous for the wild and $D f(3)$ vin $^{7}$ third chromosomes were then used as parents to produce lines hemizygous for the wild type Est6 alleles. This rescue of the lethal and deleterious wild chromosomes meant that the population was sampled randomly rather than biased in favour of homozygous viable third chromosomes.

The resolving power of cellulose acetate plate electrophoresis was calibrated against that of the sequential polyacrylamide gel electrophoresis (4 $p$ H's and 2 gel concentrations) which Keith (1983) used to distinguish mobility variants at the Est5 locus of $D$. pseudoobscura. Lines representing 25 randomly chosen Est 5 variants were tested on our cellulose acetate system in a blind trial using four buffers differing in $p \mathrm{H}(p \mathrm{H} 6 \cdot 2,7 \cdot 0,8 \cdot 5$ and $10 \cdot 4)$. A combination of any two of these buffer systems could detect all 25 electrophoretic classes, while 23 could be resolved using the $p \mathrm{H} 8.5$ buffer alone. Only the $p \mathrm{H} 8.5$ buffer was used in the analysis of the Est6 system of $D$. melanogaster as other buffers did not provide such sensitive resolution.

Cellulose acetate plate electrophoresis was carried out on adult male flies using weight-standardised mass homogenates to minimise variation in staining intensity. Approximately $70 \mathrm{mg}$ of males were weighed out from each line. Six $\mu$ l of running buffer ( $80 \mathrm{mM}$ TRIS-boric acid, $1.3 \mathrm{mM}$ EDTA, $p \mathrm{H} 8 \cdot 5)$ per mg fly were added and the flies thoroughly homogenised and centrifuged for $5 \mathrm{~min}$. The supernatant was then stored at $-20^{\circ} \mathrm{C}$. Single fly extracts for the genetic analyses were prepared in a similar way using $10 \mu$ l of running buffer per fly.

Electrophoresis was carried out on Titan III cellulose acetate plates (\#3024, Helena Laboratories, Beaumont, Texas). Sample homogenates were centrifuged a second time and the supernatants loaded onto the plates, which had been previously immersed in running buffer for $20 \mathrm{~min}$. The samples were electrophoresed for $110 \mathrm{~min}$ at $250 \mathrm{~V}(6 \mathrm{~mA} /$ plate $)$ at $4^{\circ} \mathrm{C}$ and stained with an agar overlay consisting of $5 \mathrm{ml} 0.1 \mathrm{M}$ phosphate buffer $p \mathrm{H} 6 \cdot 0,300 \mu \mathrm{l} 1$ per cent $\beta$-naphthylacetate (Sigma) in acetone, $7 \mathrm{mg}$ fast garnet GBC salt (Sigma) and $5 \mathrm{ml} 3$ per cent agar. Plates were destained in 15 percent ethanol and 5 percent glacial acetic acid.

An initial unreplicated screen of all lines was used to construct a tentative order of electrophoretic mobility classes among lines. Each line was then tested repeatedly in pair-wise comparisons against all lines of the same or adjacent putative mobility classes until a consistent classification was obtained. The pair-wise comparison of lines was carried out by running only two lines on each plate, alternating the two lines several times across the plate (fig. 1(a)). Three generations of flies were analysed to ensure consistency of classification across homogenates and generations.

\section{RESULTS}

Ten electrophoretic classes of Est6 were found among the 157 isoallelic lines (fig. 1(b)). This variation could be divided into four major mobility groups between which there were relatively large mobility differences. Three of the major groups are likely to correspond to the Est6-VF, Est6-F, and Est6-S variants of Rodino and Danieli (1972), Costa et al. (1982) and Lindsley and Zimm (1985), while the fourth major group, Est6- $F^{\prime}$ lay between Est6-VF and Est6-F. The Est6-VF and Est6-F groups contained only one class each (classes 1 and 2), the anodal mobilities of which were measured as $1 \cdot 18$ and $1 \cdot 12$ respectively, relative to the most common class (8) within the Est6-S group, the mobility of which was defined as $1 \cdot 00$ (table 1). Classes 3, 4 and 5, within the Est6-F 


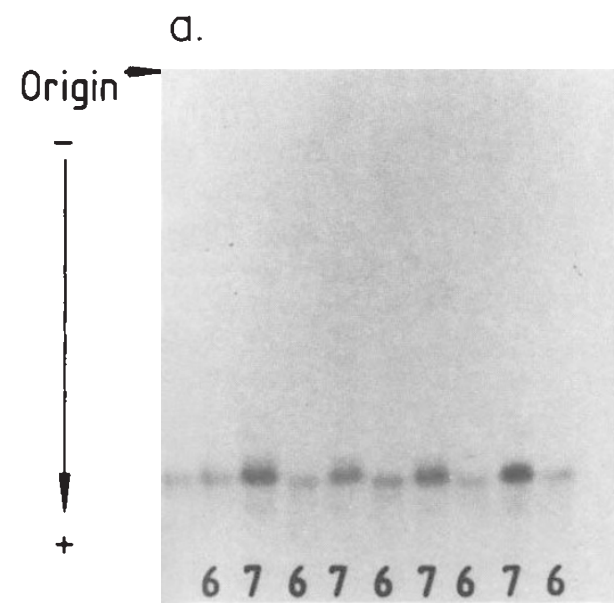

$b$

Figure 1 (a) An example of a pairwise comparison of two electrophoretic classes. Classes 6 and 7 were loaded on alternate lanes as indicated. (b) A consensus plate of Est6 electrophoretic classes. Lane numbers are synonymous to electrophoretic class.

group, showed relative mobilities of $1 \cdot 08,1 \cdot 07$ and 1.06 respectively. Classes $6,7,8$ and 9 , within the Est6-S group, showed relative mobilities of $1 \cdot 02$, $1 \cdot 01,1 \cdot 00$ and 0.99 respectively. Class 10 , also within the Est6-S group, consistently failed to show a clear band and had reduced staining intensity (fig. 1(b)), possibly due to rapid protein denaturation during electrophoresis.

Two classes were most frequent in the population, class 8, an Est6-S class, with a frequency of 55 percent, and class 4, an Est6-F class, with 22 per cent (table 1). Four classes (1, 5, 7 and 9) had

Table 1 Relative mobilities and frequencies of ten Est6 electrophoretic classes from the Coffs Harbour population $(n=157)$. Classes are numbered in decreasing order of anodal relative mobility and their correspondence with the four classes detected by standard procedures are also indicated

\begin{tabular}{|c|c|c|c|}
\hline \multicolumn{2}{|c|}{$\begin{array}{l}\text { Electrophoretic } \\
\text { class }\end{array}$} & \multirow{2}{*}{$\begin{array}{l}\begin{array}{l}\text { Relative } \\
\text { mobility }\end{array} \\
1 \cdot 18\end{array}$} & \multirow{2}{*}{$\frac{\text { Frequency }}{0.038}$} \\
\hline VF & 1 & & \\
\hline$F^{\prime}$ & 2 & $1 \cdot 12$ & 0.013 \\
\hline$F$ & $\begin{array}{l}3 \\
4 \\
5\end{array}$ & $\begin{array}{l}1.08 \\
1.07 \\
1.06\end{array}$ & $\begin{array}{l}0.006 \\
0.217 \\
0.025\end{array}$ \\
\hline$S$ & $\begin{array}{r}6 \\
7 \\
8 \\
9 \\
10\end{array}$ & $\begin{array}{l}1.02 \\
1.01 \\
1.00 \\
0.99 \\
\text { smear }\end{array}$ & $\begin{array}{l}0.006 \\
0.070 \\
0.554 \\
0.064 \\
0.006\end{array}$ \\
\hline
\end{tabular}

frequencies of 3 per cent to 7 per cent, while the remaining four classes (2, 3, 6 and 10$)$ had frequencies of 1 per cent or less. The combined frequencies of the Est6-F and Est6-S groups were 25 per cent and 70 per cent respectively, which agrees with previous frequency data ( \pm 3 per cent) from six nearby populations (Oakeshott et al., 1981).

Five crosses were set up using different combinations of the Est6 electrophoretic classes in order to check that the additional variation mapped to the same locus as the Est6-F/Est6-S difference (111,36.8 on genetic maps; Wright, 1963). The five crosses, using a total of eight homozygous lines were; classes $1 \times 2,1 \times 8,1 \times 9,4 \times 9$, and $5 \times 8$. The phenotype of the $F_{1}$ progeny from these crosses comprised the parental bands only, showing that the variation was inherited codominantly and acted in cis. The $F_{1}$ progeny of each cross were then backcrossed to one of the parental stocks and 200 backcross progeny electrophoresed for each original cross. Only parental bands were seen among a total of 1000 backcross progeny analysed. The absence of recombination products among these progeny precludes the existence of effects due to modifier loci further than 0.30 to 0.46 centimorgans from the Est 6 locus $(P<0.05$ and $P<0 \cdot 01$, respectively). This suggests that the additional variants map to the Est 6 locus, although it is admitted that classes 3, 6, 7 and 10 were not involved in the crosses as they were available as hemizygous lines only.

All four chromosomes containing class 5 Est 6 were homozygous viable; on the other hand, four 
classes, 3, 6, 7 and 10, were only found in chromosomes cultured as hemizygotes (wild/Df(3) vin $^{7}$ ) because of their poor homozygous viability. These associations suggest the existence of gametic disequilibrium between particular Est6 electrophoretic classes and detrimental genes on chromosome III. Such disequilibrium was confirmed by the segregation ratios in the backcross progeny for the cross of the wild chromosomes to the TM3 balancer. Analysis of these ratios revealed that two electrophoretic classes, 5 and 9, were each associated with higher mean homozygous third chromosome viabilities (relative to their viabilities as heterozygotes with TM3) than the other eight classes $(P=0.06$, and $P=0.03$, respectively, and see fig. 2).

The crossing program to make the less viable lines hemizygous against the $D f(3) v_{\text {in }}^{7}$ deficiency provided a further viability test. The ratio of wild/Df(3) vin $^{7}$ hemizygotes to TM3/Df(3) vin ${ }^{7}$ hemizygotes in the progeny of each cross could only be disturbed from $1: 1$ by the action of lethal or deleterious genes in the region around Est6 uncovered by the deletion. Analysis of these ratios revealed one line from class 9 with a lethal gene in the Est6 region while deleterious genes in the region (viabilities less than 45 percent of TM3 heterozygotes, which were significantly less than 100 percent at $P<0.05$ ) were identified in eight lines, five in class 8 and one each in classes 4,7 and 9. However, the distribution of these nine lethal and deleterious genes across Est6 electrophoretic classes was not significantly different from random $\left(\chi_{8}^{2}=2 \cdot 6, P>0.05\right)$.

The $\operatorname{In}(3 L) P$ inversion was found seven times among the 157 lines and all seven occurrences were in lines from class 4. This association between Est6 class 4 and $\operatorname{In}(3 L) P$ was highly significant $\left(\chi_{1}^{2}=\right.$ $26 \cdot 9, P<0 \cdot 0005)$.

Thirteen lines representing six of the seven Est6 alleles which Cochrane (1976) and Cochrane and Richmond (1979) isolated by thermostability criteria were also electrophoresed. Two of these classes were slow variants designated $S 1$ and $S 2$ by the authors above, while four were fast variants designated $F 1, F 2, F 3$ and $F 4$. The single $S 1$ line typed to our electrophoretic class 9 , while two $S 2$ lines typed to class 8 . However, the other ten lines representing the four Est6-F thermostability classes clustered within two electrophoretic classes (4 and 5). In particular, both these electrophoretic classes were found among lines from each of the

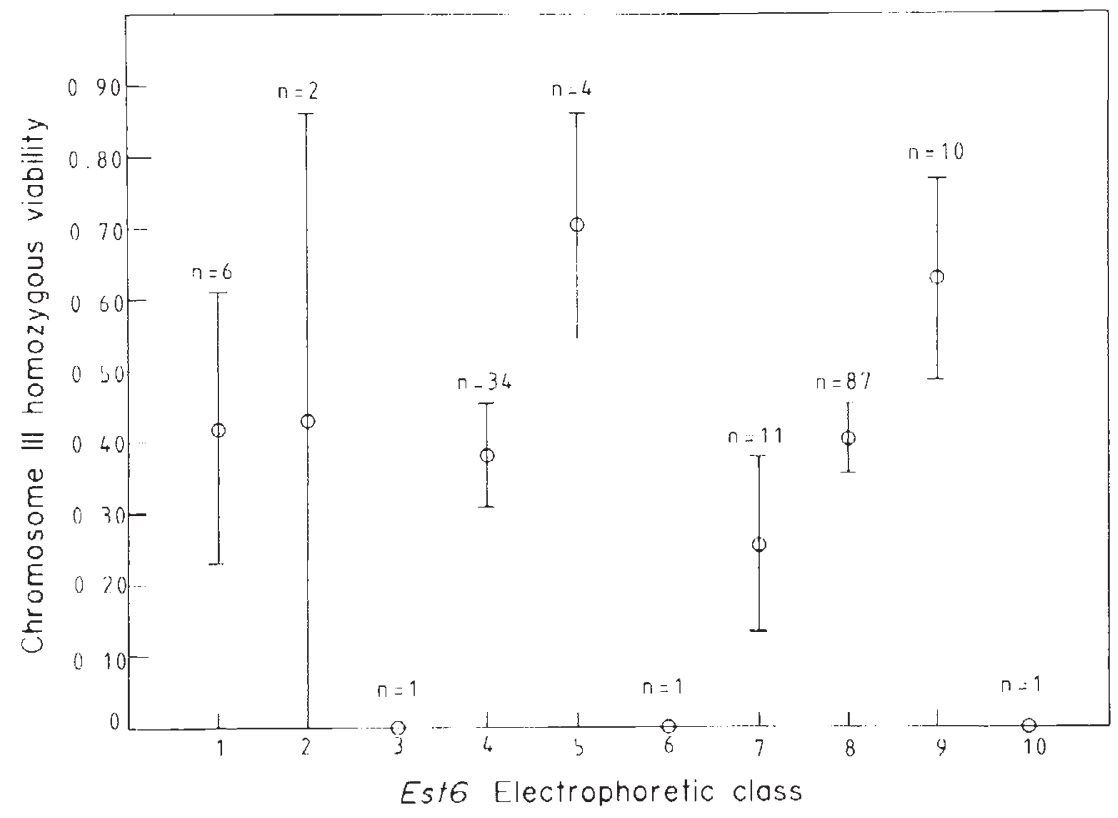

Figure 2 Mean chromosome III homozygous viabilities ( \pm s.e.) derived from segregation ratios in the backcross progeny for the cross of the wild chromosome to the TM 3 balancer. $n=$ the number of lines in any given class. 
Table 2 A comparison of electrophoretic and thermostability criteria for detecting variation at the Est6 locus. Thirteen lines from six* thermostability classes were electrophoresed (lines and thermostability data from Cochrane and Richmond, 1979). The numbers in the body of the table represent the number of lines scored for any given category.

\begin{tabular}{lllllll}
\hline \multirow{2}{*}{$\begin{array}{l}\text { Electrophoretic } \\
\text { class }\end{array}$} & \multicolumn{6}{l}{ Thermostability class } \\
& $F 1$ & $F 2$ & $F 3$ & $F 4$ & $S 1$ & $S 2$ \\
\hline 4 & 1 & 2 & 1 & & & \\
5 & 2 & & 1 & 3 & & \\
8 & & & & & & 2 \\
9 & & & & & 1 & \\
\hline
\end{tabular}

* Lines representing the seventh thermostability class $(S 3)$ were not available

thermostability classes $F 1$ and $F 3$ and, conversely, there were three thermostability classes in each of the electrophoretic classes 4 and 5 (table 2).

\section{DISCUSSION}

The application of high resolution cellulose acetate electrophoresis has resolved ten Est6 electrophoretic classes among 157 isoallelic lines from a single population of $D$. melanogaster (table 1 , fig. 1(b)). Standard electrophoretic techniques (Oakeshott et al., 1981; Cabrera et al., 1982; Anderson and Oakeshott, 1984) would have detected only four electrophoretic classes. Genetic test crosses were carried out among six of the ten classes and the results were consonant with the hypothesis that the additional variation mapped to the Est6 structural locus.

Two of the ten electrophoretic classes ( 5 and 9) were associated with greater than average chromosome III viability (fig. 2). Viability effects are known to be associated with inversions (Nassar, 1968; Watanabe and Yamazaki, 1976), but in this study lines carrying the $\operatorname{In}(3 L) P$ inversion, which was in gametic disequilibrium with class 4 , did not differ significantly in viability from other lines.

Voelker et al. (1978) reported a significant positive association between the Est6-F allele and the $\operatorname{In}(3 L) P$ inversion in North American populations of $D$. melanogaster. In this study, $\operatorname{In}(3 L) P$ was only found in lines bearing Est 6 class 4 (the most frequent Est6-F class), in which it occurred in seven out of 34 chromosomes. Thus, an association of Est6-F with $\operatorname{In}(3 L) P$ has now been documented for two continents in different hemispheres and it would seem that the gametic disequilibrium between this inversion and Est6-F is widespread and relatively old. It is therefore possible that the population dynamics of Est 6 alleles may be at least in part determined by those of the larger chromosomal polymorphism. In particular, it could be argued that the latitudinal clines for the major Est6-F and Est6-S alleles (Anderson and Oakeshott, 1984) may be the outcome of their disequilibrium with $\operatorname{In}(3 L) P$, the frequencies of whicil also vary clinally with latitude (Knibb et al., 1981). However, this latter argument is discounted by the fact that the same cline for Est6 exists in D. simulans, a species with no known polymorphic inversions and the same major Est6 variants (Ashburner and Lemeunier, 1976; Anderson and Oakeshott, 1984).

The finding of ten electrophoretic classes in this study compares with the 27 Est6 electrophoretic classes reported for $D$. simulans by De Albuquerque and Napp (1981) from among over 2000 third chromosomes from two South American populations. However, in the latter study, Est6 phenotypes were simply scored in wild/caught males whereas our classification was based on repeated pair-wise comparisons among extracted isoallelic lines. It is our experience, consonant with that of Keith (1983) and Keith et al. (1985), that the use of isoallelic lines and repeated pairwise testing is essential to confirm the classification of variants with small relative mobility differences.

It is possible that a small number of electrophoretic variants still remain undetected in the present sample since our cellulose acetate system only detected 23 of the 25 Est 5 variants in the $D$. pseudoobscura lines we tested (see materials and methods). Moreover, application of our system to 13 other lines of $D$. melanogaster representing six different Est 6 thermostability variants indicated that the variants detected by the two criteria are essentially uncorrelated (table 2). Electrophoresis may more readily detect substitutions on the outside of the Est6 molecule affecting its surface charge. On the other hand, thermostability criteria may be more likely to detect internal substitutions affecting the stability of the tertiary protein structure. If it were presumed that the differences detected by the two tests are completely independent, then one might predict that a larger sample would reveal three or four thermostability variants within each of the ten electrophoretic classes at the Est6 locus.

It is therefore clear that Est6 is a highly variable locus and now joins two other loci showing similar degrees of polymorphism (Est5 and $X d h$ of $D$. pseudoobscura: Coyne, 1982; Keith, 1983; Keith et al., 1985). The results of many previous genetic analyses of Est6 now require re-appraisal. With respect to its population genetics it is important 
to determine which of the ten electrophoretic variants (or seven thermostability variants) underlies the Est6-F/Est6-S clines in both $D$. melanogaster and D. simulans (Anderson and Oakeshott, 1984). Given the highly variable nature of the Est6 locus, it may well be that the major electrophoretic phenotypes showing the clinal variation are acting as markers for some other more physiologically relevant polymorphism in the gene. We are presently collecting comparative nucleotide sequence data in order to investigate this question, and to identify the amino acid substitutions distinguishing the major and minor electrophoretic differences, and the sites responsible for the thermostability variation.

Acknowledgements We thank Dr Tim P. Keith for the gift of the 25 lines of $D$. pseudoobscura typed for Est5. We are also indebted to Dr. Wayne R. Knibb for analysing the lines of $D$. melanogaster for chromosomal polymorphism. We thank Ann Y. Game, Jill Karotam, Elisabeth A. van Papenrecht, Marlene Saad, C. Lynne Mclntyre, Robyn J. Russell and Steven W. McKechnie for stimulating discussions and comments on the manuscript.

\section{REFERENCES}

AKAM, M. \&:, ROBERTS, D. B., RICHARIDS, G. P. AND ASHBUR NER, M. 1978. Drosophila: the genetics of two major larval proteins. Cell, 13, 215-225.

ANIIRSON, P. R. ANI) (OAKESHOTT, J. G.. 1984. Parallel geographic patterns of allozyme variation in two sibling Drosophila species. Nature, 308, 729-731.

ASIBUUNER, M. AND LEMEUNIER, F. 1976. Relationships within the melanngaster species subgroup of the genus Drosophila (Sophophora). 1. Inversion polymorphisms in $D$. melanogaster and D. simulans. Proc. Royal Soc. Lond. B., 193, 137-157.

CABRERA, V. M., GONZAI.EZ, A. M. I.ARRUGA, J. M. ANI GULL.ON, A. 1982. Electrophoretic variability in natural populations of Drosophila melanogaster and Drosophila simulans. Genetica, 59, 191-201.

COCHRANE, B. J. 1976 . Heat stability variants of esterase- 6 in Drosophila melanogaster. Nature, 263, 131-132.

(OCHRANE, B. I. AND RICHMOND, R. C. 1979. Studies of esterase- 6 in Drosophila melanogaster. 11. The genetics and frequency distributions of naturally occurring variants studied by electrophoresis and heat stability criteria. Genetics, 93, 461-478.

COSTA, R., 1)ANIELI, (i. A., AND NIGiR(), L. 1982. Genetics and biochemistry of esterase-6 in Drosophita melanogaster. In Lakovaara, S. (ed.) Advances in genetics, development, and evolution of Drosophila. Plenum Press, New York and London, pp. 285-288.

(')YNE, J. A. 1982. Gel electrophoresis and cryptic protein variation. In Rattazzi, M. C., Scandalios, J. (j., and Whitt, G. S. (eds.), Isozymes: C'urrent topics in biological and medical research. Alan R. Liss, New York. Vol. 6, pp. 1-32.

DI: AL.BUQUTR(IIE, M. R., ANI) NAPP, M. 1981. Genetic variability at the esterase-6 locus in natural populations of Drosophila simulans in relation to environmental heterogeneity. Genetics, 98, 399-407.
GILBERT, I). (i. 1981. Ejaculate esterase-6 and initial sperm use by female Drosophila melanogaster. J. Insect. Physiol., 27, $641-650$

KEITH, T. P. 1983. Frequency distribution of esterase-5 alleles in two populations of Drosophila pseudoobscura. Genetics, $105,135-155$.

KEITH, T, P., BROOKS, I, I), L,FWONTIN, R. C. MARTINEZ CRUZAIOO, J. (․ AND RIGBY, I). L. 1985. Nearly identical allelic distributions of xanthine dehydrogenase in two populations of Drosophila pseudoobscura. Mol. Biol. Evol., 2, 206-216.

KIMURA, M. 1983. The neutral theory of molecular evolution. Cambridge University Press, Cambridge.

KNIBB, W. R., OAKISHOTT, J. G. ANI) GIBSON, J. B. 1981. Chromosome inversion polymorphisms in Drosophila melanogaster. I. Latitudinal clines and associations between inversions in Australian populations. Genetics, 98, $833-847$

1.FONTIN, R. C. 1974. The genetic basis of evolutionary change. Columbia University Press, New York.

LINDSLEY, I). L. AND GRELL, F. H. 1968. The genetic variations of Drosophila melanogaster. Carnegie Inst. Wash. Publ., 627 , pp. 472.

LINDSLEY, 1). I. AND ZIMM, (j. 1985. The genome of Drosophila melanogaster; progress report. DIS, 62, 108-109

NASSAR, R. F. 1968. Relative fitness of a third chromosome inversion in Drosophila melanogaster. Aust. J. Biol. Sci., 21, $1179-1186$.

Nt:VO, E. 1978. Genetic variation in natural populations: patterns and theory. Theor. Pop. Biol., 13, 121-177

OAKESHOTI, J. G., CHAMBI:RS, G. K., GIBSON, J. B. AND WILI. COCKS, D). A. 1981. Latitudinal realtionships of esterase-6 and phosphoglucomutase gene frequencies in Drosophila melanogaster. Heredity, 47, 385-396.

RICHMOND, R. C. AND SENIOR, A. 1981. Esterase-6 of Drosophila melanogaster: kinetics of transfer to females, decay in females, and male recovery. J. Insect Physiol., 27, 849-853.

ROIDINO, I:. AND DANIELi, (i. A. 1972. Three more alleles at the Est6 locus in D. melanogaster. Dis, $48,77$.

SHEFHAN, K., RICHMONI), R. C. AND ('OCHRANE, B. J. 1979. Studies of esterasc-6 in Drosophila melanogaster. III. The developmental pattern and tissue distribution. Insect Bioch., 9, 443-450.

SCOTT, 1).S. 1986. Inhibition of female Drosophila melanngaster remating by a seminal fiuid protein (esterase-6). Evol. 40, $1084-1091$.

VOFI.KER, R. A., (OOCKLRHAM, C. ( .,.OHNSON, F. M., SCHAFFI:R, H. E., MUKAI, T. AND METTI,ER, L. E. 1978. Inversions fail to account for allozyme clines. Genetics, 88, 515-527.

WATANABE, T. K. AND YAMAZAKI, T, 1976. Evidence for coadaptation: negative correlation between lethal genes and polymorphic inversions in Drosophila melanogaster. Genetics, 82, 697-702.

WRIGHT, T. R. F. 1963. The genetics of an esterase in Drosophila melanogaster. Genetics, 48, 787-801.

YAMAZAKI, T., KUSAKABI, S., TACHIDA, H., ICHINOSF, M., YOSHIMARI, H., MATSUO, Y. AND MUKAI, T. 1983. Reexamination of diversifying selection of polymorphic allozyme genes by using population cages in Drosophila melanogaster. Proc: Nall. Acad. Sci. U.S.A., 80, 5789-5792. 